\title{
Failure Modes in Concrete Repair Systems due to Ongoing Corrosion
}

\author{
Mladena Luković, ${ }^{1}$ Branko Šavija, ${ }^{1}$ Guang Ye, ${ }^{1,2}$ Erik Schlangen, ${ }^{1}$ and Klaas van Breugel ${ }^{1}$ \\ ${ }^{1}$ Delft University of Technology, Delft, Netherlands \\ ${ }^{2}$ Magnel Laboratory for Concrete Research, Ghent University, Ghent, Belgium \\ Correspondence should be addressed to Mladena Luković; m.lukovic@tudelft.nl
}

Received 21 September 2016; Accepted 26 February 2017; Published 2 April 2017

Academic Editor: Cristina Leonelli

Copyright (C) 2017 Mladena Luković et al. This is an open access article distributed under the Creative Commons Attribution License, which permits unrestricted use, distribution, and reproduction in any medium, provided the original work is properly cited.

Corrosion of steel reinforcement is the main cause of deterioration in reinforced concrete structures. It can result in cracking and spalling of the concrete cover. After the damaged cover is repaired, reinforcement corrosion might continue and even accelerate. While the development of the corrosion cell is difficult to control, the damage can be possibly delayed and controlled by use of a suitable repair material. The lattice fracture model is used in this paper to investigate the performance of strain hardening cementitious composite (SHCC) in concrete repair systems exposed to ongoing corrosion. Numerical results were verified by experimental tests when SHCC, nonreinforced material (repair mortar), and commercial repair mortar are used as repair materials. In experiments, reinforcement bars (surrounded by a repair material) were exposed to accelerated corrosion tests. The influence of the substrate surface preparation, the type of repair material, the interface, and the substrate strength on the resulting damage and failure mode of repair systems are discussed. In general, SHCC repair enables distributed cracking with small crack widths, up to several times smaller compared to repair mortar. Furthermore, more warning signs prior to the final failure are present in the SHCC repair system.

\section{Introduction}

Corrosion of reinforcement is the most common deterioration mechanism affecting reinforced concrete structures [1]. In general, steel reinforcement is protected from corrosion by a passive film which is formed on its surface in highly alkaline concrete. However, if this protection is lost (which could happen due to either chloride ingress [2] or carbonation [3]), the steel will begin to corrode. During corrosion, the corrosion products expand and exert pressure on the surrounding concrete. Already at moderate levels of corrosion, generated tensile stresses lead to cracking of the concrete cover [4,5]. In the engineering practice, cracked and chloride contaminated concrete is removed, the steel bar is cleaned, and the damaged concrete is replaced with a repair material, resulting in patch repair. Nevertheless, corrosion of the steel bar often continues after the repair, due to differences in electrochemical behaviour of the old and new concrete, inadequately cleaned reinforcement and corrosion pits [6], high permeability of the repair material or the interface during the hardening period, or microcracks in the repair material due to the restrained shrinkage [7]. This could result either in an incipient anode phenomenon (when the rust is produced not in the repair itself, but in the nearby concrete) or in further corrosion occurring within the repaired location (Figure 1) [6-8]. Ongoing corrosion in a repair system is one of the most common causes for premature failure of patch repairs. As the development of the corrosion cell depends on many parameters and is difficult to control, in cases when corrosion is continuing inside the repair material itself, the occurrence of damage can be controlled by use of a suitable repair material.

In general, service life or reinforced concrete structures are considered to end once the corrosion starts. This is because the modelling and prediction of the corrosion induced damage contain high levels of uncertainty. As a result, the aforementioned approach for service life prediction is (very) conservative. This is especially true for 


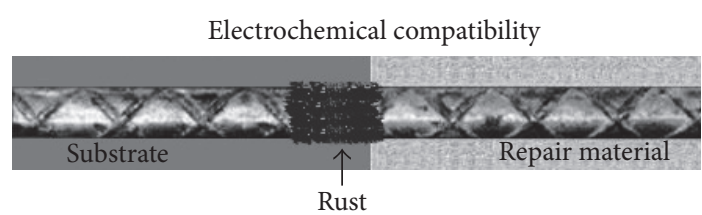

(a)

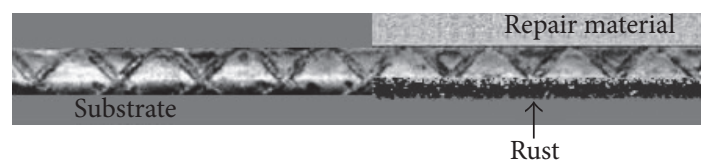

(b)

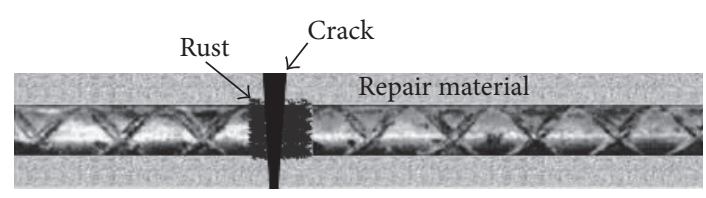

(c)

FIgUre 1: Possible locations of continued corrosion in concrete repair systems ( (a) corrosion developing in the substrate due to incipient anode phenomenon at the perimeter of repair, (b) corrosion developing in the substrate at the bottom of the repair if the bar is half embedded in existing, chloride-contaminated concrete, and (c) corrosion developing in the repair material due to inadequate cleaning, restrained shrinkage cracking, and high permeability), adopted from [7].

repair systems, which are rarely crack-free and where the time needed for the onset of corrosion may be very short. Therefore, for more practical service life predictions, it seems important to investigate corrosion induced damage propagation in repair systems.

Most investigations of strain hardening cementitious composite (SHCC) for repair applications have mainly focused on the material's mechanical performance and deformational capacity in flexural and restrained shrinkage tests $[9,10]$. Recently, its applicability for patch repair against steel corrosion has been studied [11]. It was shown that SHCC patch repair, due to its small crack widths, effectively suppressed chloride penetration and prevented the occurrence of reinforcement corrosion. However, the concrete substrate that was used in these experiments was free from chloride contamination. Furthermore, cracks that were introduced in the repair system prior to corrosion testing were a result of an externally applied mechanical loading and not the corrosion process itself. The performance of patch repair systems when continued corrosion is the underlying cause of pressure build-up is still not investigated. This can be relevant when high ductility of the repair material is needed to accommodate the high local imposed pressure.

In this paper, the feasibility and implications of using SHCC in concrete overlays and patch repairs with ongoing corrosion in the steel bar surrounded by the repair material are studied. Reinforcement imbedded in different types of repair materials was exposed to accelerated corrosion, and failure modes of repair systems were investigated. The damage development is then simulated with the lattice model. The influence of critical parameters (interface strength, surface

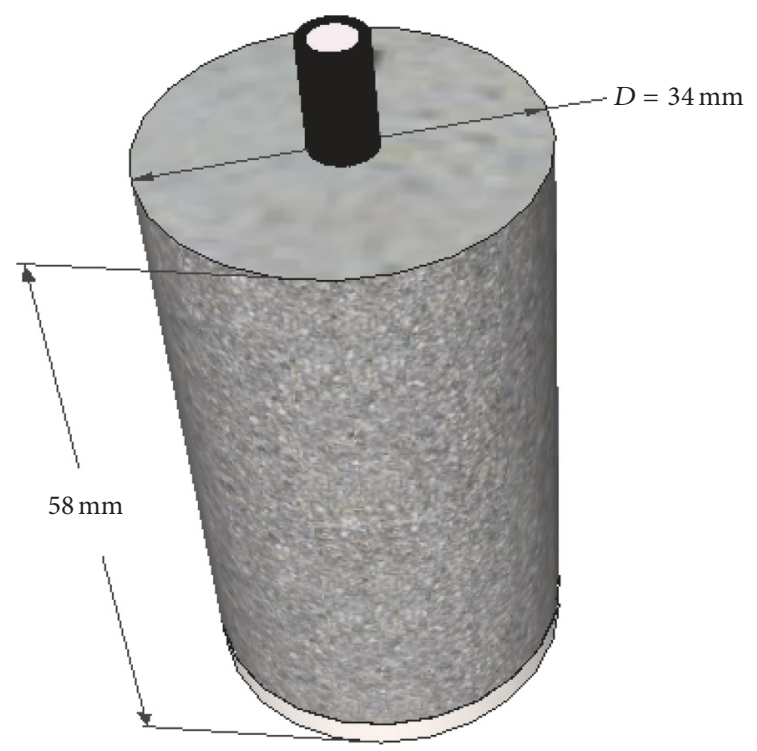

FIGURE 2: Specimen geometry for the accelerated corrosion test used in [13].

roughness, and substrate strength) on fracture behaviour of the repair system is studied. The aim of this paper is not to study the corrosion induced cracking, which has been a topic of numerous studies [5, 12-14], but rather to focus on failure behaviour of different repair systems during ongoing corrosion and how this behaviour changes with aforementioned parameters. This was not done in the past but could provide important knowledge for damage development in repair practice.

\section{Materials and Methods}

2.1. Experimental Procedure. Fracture behaviour of SHCC mixtures and the same mixture without fibres (i.e., mortar) was previously studied [15]. In that study, prior to casting, a smooth steel rod with a diameter of $6 \mathrm{~mm}$ was placed in the centre of each specimen as a reinforcement bar (Figure 2). Specimens were left in laboratory conditions $\left(\mathrm{T}=20^{\circ} \mathrm{C}\right.$, $\mathrm{RH}=50 \%$ ) for 10 days before demoulding and preparing for accelerated corrosion test. Subsequently, each specimen was immersed in a container with saturated calcium-hydroxide solution, wrapped in a titanium mesh to act as a counter electrode, and connected to a Direct Current (DC) regulator to enforce corrosion. Corrosion induced cracking of the SHCC and the mortar specimen after different exposure times were monitored by using three-dimensional microcomputed tomography (CT scan). More information about these experiments can be found in [15].

In this study, similar tests were performed on repair systems in order to study the performance of SHCC as a repair material in case of ongoing corrosion inside the repair material. Three different repair materials were used: SHCC, nonreinforced repair mortar (further referred to as repair mortar), and commercial repair material. Mix composition of SHCC is given in Table 1 while nonreinforced repair material 
TABLE 1: Mix proportion of SHCC mix (weight \%).

\begin{tabular}{lccccc}
\hline CEM I 42.5N & Limestone powder & Blast furnace slag & Water/powder ratio & Superplasticizer & PVA fiber (by volume, \%) \\
\hline 1 & 3.33 & 2.33 & 0.26 & 0.005 & 2 \\
\hline
\end{tabular}

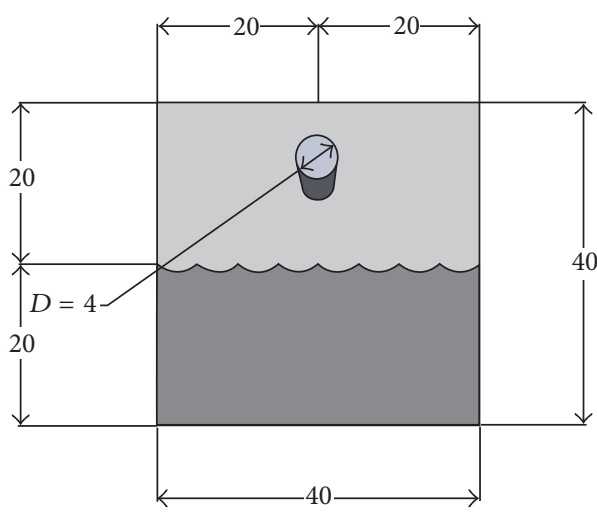

(a) Test set-up

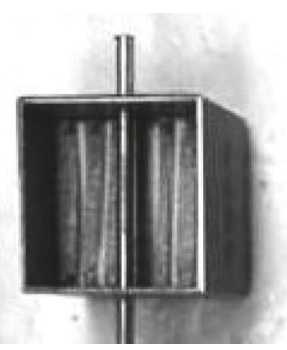

(b) Smooth and grooved surface substrate

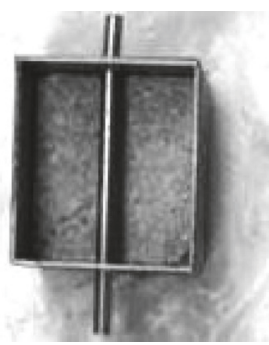

(c) Casting of the repair materials

Figure 3: Preparation of the repair systems for accelerated corrosion tests.

TABLE 2: Comparison of properties of commercial mortar and SHCC.

\begin{tabular}{lcccc}
\hline & $\begin{array}{c}\text { w/p } \\
{[-]}\end{array}$ & $\begin{array}{c}\text { Density } \\
{\left[\mathrm{kg} / \mathrm{m}^{3}\right]}\end{array}$ & $\begin{array}{c}E \\
{[\mathrm{GPa}]}\end{array}$ & $\begin{array}{c}\text { fc } \\
{[\mathrm{GPa}]}\end{array}$ \\
\hline Commercial mortar & 0.16 & 1950 & 16 & 45 \\
SHCC & 0.26 & 2025 & 18.5 & 40 \\
\hline
\end{tabular}

is the same mixture only without the fibres. The commercial repair material (Cuglacrete Hoogoven A middle R3) was chosen such that it has similar properties as the SHCC used in this study (comparison of properties is given in Table 2). It is a polymer modified blast furnace slag based mortar with polyacrylonitrile fibres. Note that these fibres do not enable strain hardening behaviour.

Repair materials were cast on top of a 2-year-old mortar substrate. The test set-up is shown in Figure 3(a). The substrate was made with a smooth and a grooved surface (Figure 3(b)). Both the height and the width of the grooves were $3 \mathrm{~mm}$. Once the substrates were prepared (Figure 3(b)), the repair material was cast (Figure 3(c)). Specimens were demoulded after $24 \mathrm{~h}$ and sealed cured for six days. Subsequently, they were left to dry for $72 \mathrm{~h}$ in laboratory conditions $\left(\mathrm{T}=20^{\circ} \mathrm{C}, \mathrm{RH}=50 \%\right)$. Finally, specimens were exposed to accelerated corrosion by applying an external voltage (Figure 4(a)). Since all specimens were tested at the same time, voltage (instead of current) was used as a controlling parameter. The voltage was increased twice during the test to speed up the onset of damage (Figure 4(b)). At the end of the experiment, all samples were impregnated with fluorescent epoxy to investigate the crack patterns. The results were then compared to simulated cracks. In parallel to these tests, compression tests were performed on the repair materials and the substrate. These tests were performed on $40 \times 40 \times$ $40 \mathrm{~mm}^{3}$ specimens.

2.2. Modelling Procedure. In order to investigate the mechanical performance of a repair system subjected to continued reinforcement corrosion, the lattice model is used [16, 17]. In the lattice model, the material is discretised as a network (lattice) of beam elements which can transfer forces. The material microstructure/mesostructure can be mapped onto the mesh by assigning different mechanical properties to beams in the lattice. In this way, fracture behaviour of composite quasi-brittle materials such as cement paste [18], concrete [16], or graphite [19] can be simulated. Usually all the single elements have linear elastic properties. In each loading step, an element that exceeds the limit stress or strain capacity is removed from the mesh. The analysis procedure is then repeated until a predetermined failure criterion for the simulated specimen is achieved. In this way realistic crack patterns can be obtained.

The procedure to generate the network is as follows [20]:

(i) A cubical grid is chosen (square for 2D lattice).

(ii) In each cell of the square (cube for 3D lattice), a random location for a lattice node is selected. First the nodes are randomly positioned inside a subcell of size $s$ in a regular grid with size A (Figure 5). The ratio s/A is defined as randomness of a lattice and here it is set to be 0.5 . This means that some disorder is built into the lattice mesh itself.

(iii) Always the three nodes (four nodes for 3D) which are closest to each other are connected by beam elements 


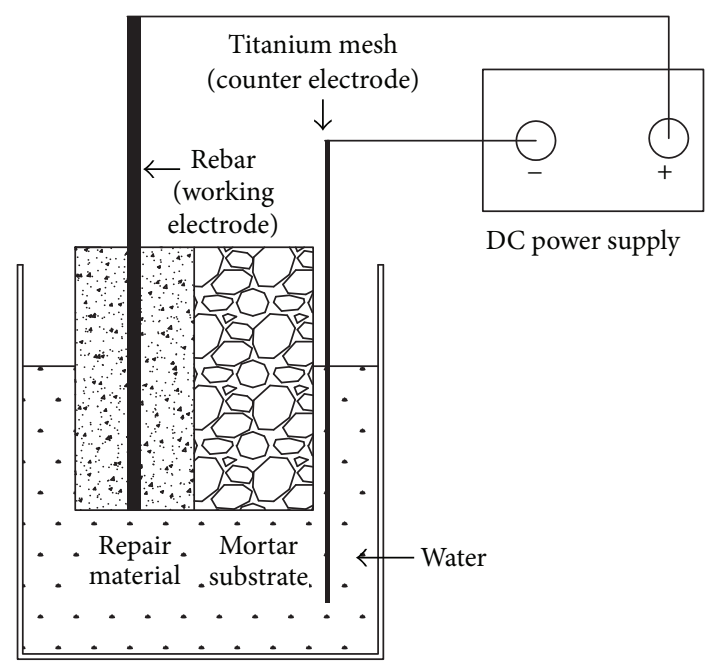

(a) Set-up for corrosion test

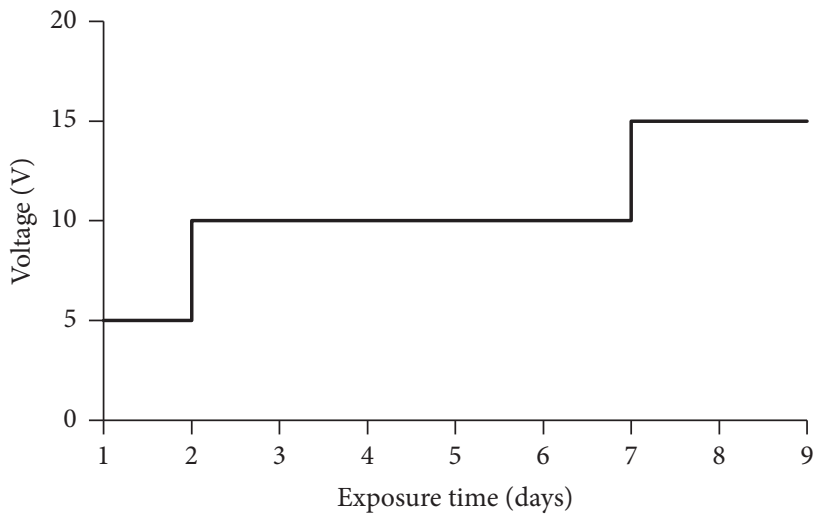

(b) Applied voltage in accelerated corrosion test

FIGURE 4: Accelerated corrosion test.

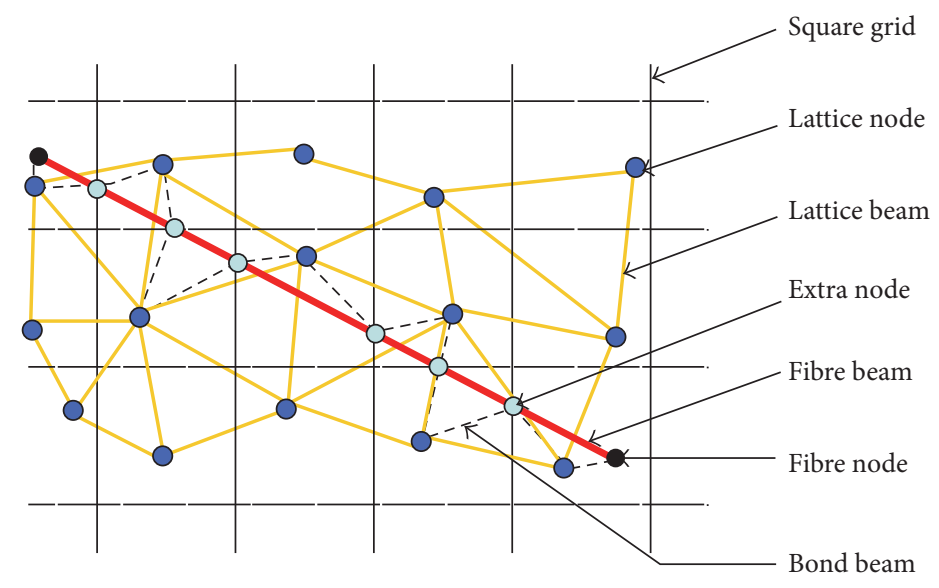

FIGURE 5: Schematic 2D representation of generation of fibre-lattice [14].

using Delaunay triangulation. Each node of the 3D system has 6 degrees of freedom ( 3 translations and 3 rotations)

(iv) The beams which belong to each phase are identified by overlapping material layers (i.e., concrete/mortar substrate and repair material) on top of the lattice. Interface elements are generated between substrate nodes and repair material nodes. In Figure 5, generation of interface elements for the smooth and rough (grooved) substrate surface is presented.

(v) Fibre elements are added in the repair material according to a chosen volume content ( $2 \%$ by volume in case of SHCC), fibre length, and diameter. The location of the first node of each fibre is chosen randomly in the specified volume and a random direction is defined which determines the position of the second node. If the second node is outside of the mesh boundary, then it is automatically cut off and accounted for in order to ensure preservation of prescribed volume content.

(vi) Extra nodes inside the fibres are generated at each location where the fibre crosses the square (in $3 \mathrm{D}$ cubical) grid.

(vii) Fibre interface elements are generated between fibre nodes and the matrix nodes in the neighbouring cell. Also, the end nodes of the fibres are connected with an interface element to the matrix node in the cell where the fibre end is located (Figure 5).

(viii) An element can fail either in tension or in compression, when the stress exceeds its strength. For the fracture criterion, only axial forces are taken into account to determine the stress in the beams.

(ix) In order to take material heterogeneity of the substrate into account, either a computer-generated material structure or a material structure obtained by micro-CT scanning $[21,22]$ can be used. Here, the 


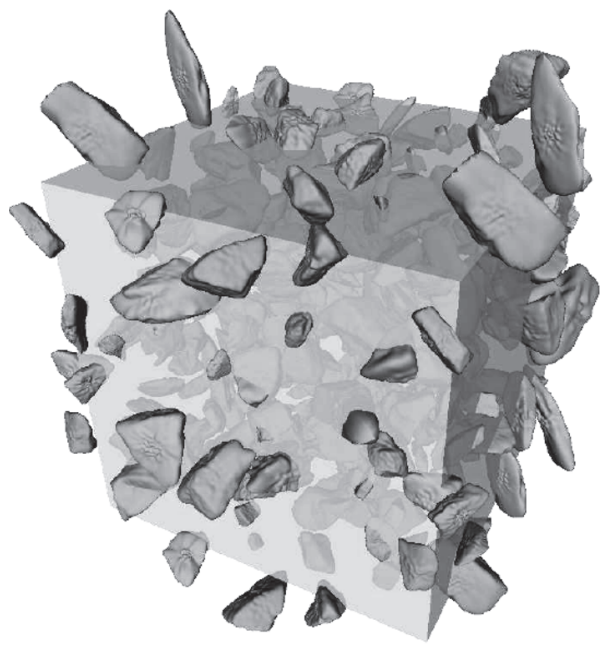

(a)

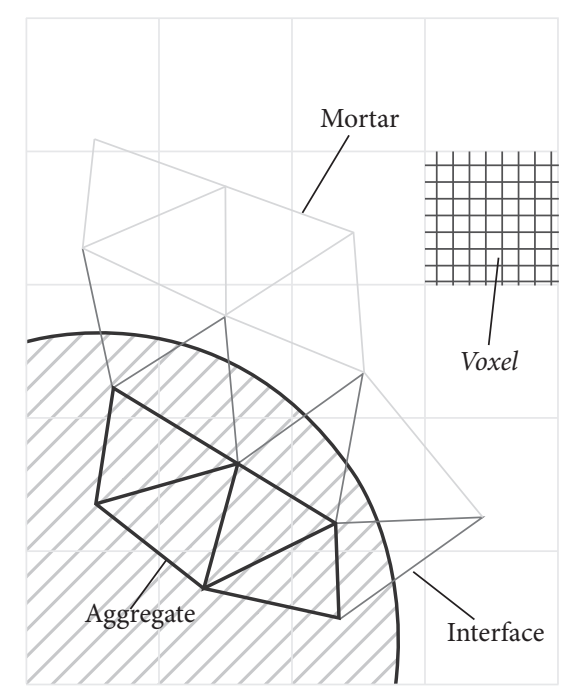

(b)

FIGURE 6: (a) Aggregates in the concrete substrate generated by Anm model [22]; (b) two-dimensional overlay procedure for generation of the lattice model in interface zone between aggregate and substrate mortar (ITZ) [23].

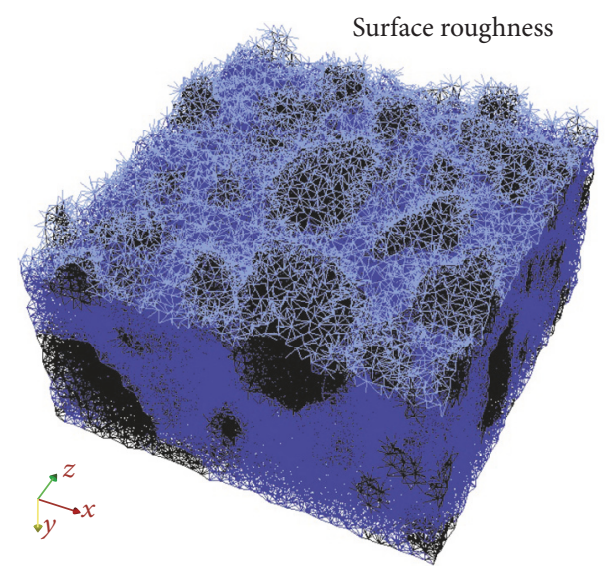

FIGURE 7: Simulated rough substrate material structure, showing coarse aggregates (black) and mortar (blue).

concrete mesostructure was simulated using the Anm material model originally developed by Garboczi [23] and implemented in a 3D parking algorithm by Qian et al. [24]. It is based on placing multiple irregular shape particles separated into several sieve ranges into a predefined empty container. Aggregates smaller than $4 \mathrm{~mm}$ are not explicitly modelled and, together with the cement matrix, are considered to constitute the mortar phase.

(x) Material overlay procedure (Figure 6(a)) is used and further extended for including the aggregates in the concrete substrate. Interface elements are generated between the substrate nodes and the repair material nodes (interface MS/RM) while aggregate-paste interface (ITZ) elements are generated between the mortar nodes and the aggregates (Figure 6(b)). In this manner, different mechanical properties are assigned to different phases (Table 3). Figure 7 shows the
TABLE 3: Input values for lattice fracture model ( $E$ stands for the modulus of elasticity, $f_{t}$ stands for the tensile strength, and $f_{c}$ for the compressive strength of elements).

\begin{tabular}{lccc}
\hline Element & $E[\mathrm{GPa}]$ & $f_{t}[\mathrm{MPa}]$ & $f_{c}[\mathrm{MPa}]$ \\
\hline Matrix (repair mortar, RM) & 20 & 3.5 & 35 \\
Fibre & 40 & 7380 & 7380 \\
Interface (matrix/fibre) & 20 & 90 & 900 \\
Mortar substrate & 25 & $4 / 5$ & $40 / 50$ \\
Aggregate & 70 & 8 & 80 \\
ITZ & 15 & $2.5 / 3.5$ & $25 / 35$ \\
Interface (MS/RM) & 15 & $1 / 3$ & $10 / 30$ \\
\hline
\end{tabular}

substrate with exposed aggregates before "casting" of the repair material. As already explained, interface elements in the model are larger than real interfaces. However, interface properties in simulations are fitted such that they represent the effect of the real interface size.

The performance of repair systems with repair mortar (without PVA fibres) and SHCC used as repair materials are simulated. The volume percentage of the crushed stone in the simulated concrete substrate is $30 \%$. This should approximately correspond to the amount of coarse aggregates in the concrete. $67 \%$ of coarse aggregates are in the sieve range $(8,16) \mathrm{mm}$ and $33 \%$ are in the sieve $(4,8) \mathrm{mm}$ (see Table 1). In the simulations, apart from the interface strength, also the strength of the substrate was varied. This is done in order to account for differences in strength between the repair material and the concrete substrate, which usually exists in experiments and practice. In one of the simulations, therefore, the mortar and the ITZ strength's in the substrate were $5 \mathrm{MPa}$ and $3.5 \mathrm{MPa}$, respectively (instead of $4 \mathrm{MPa}$ and 2.5 MPa, Table 1). 


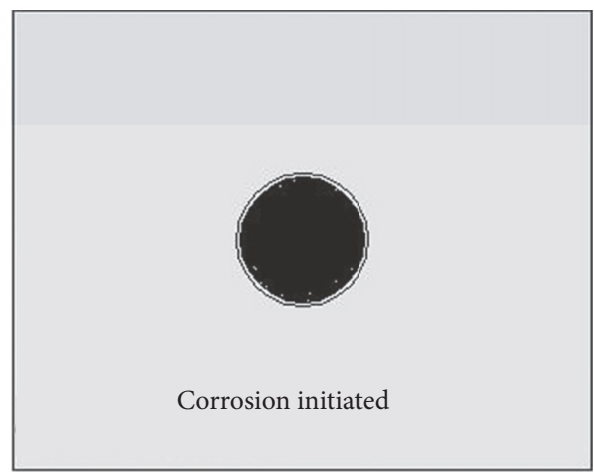

(a)

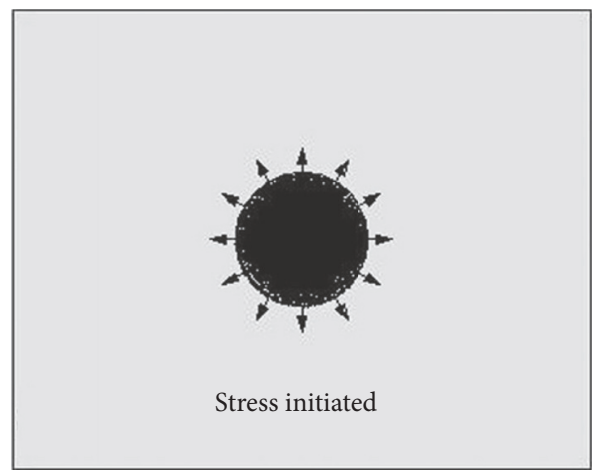

(c)

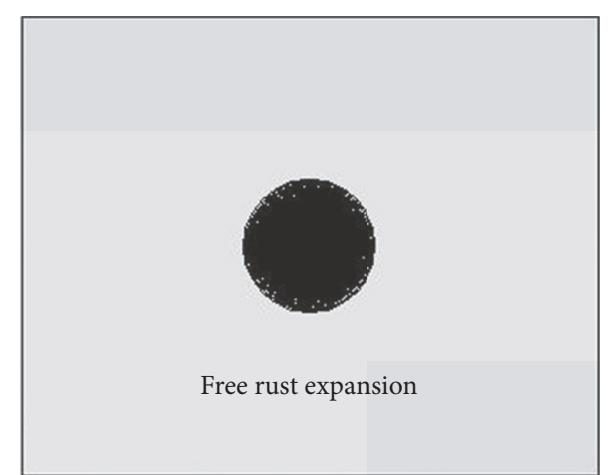

(b)

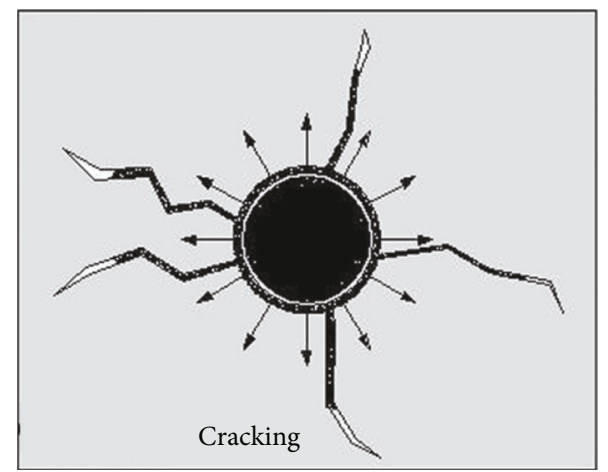

(d)

FIGURE 8: (a-d) Illustration of the corrosion process [12].

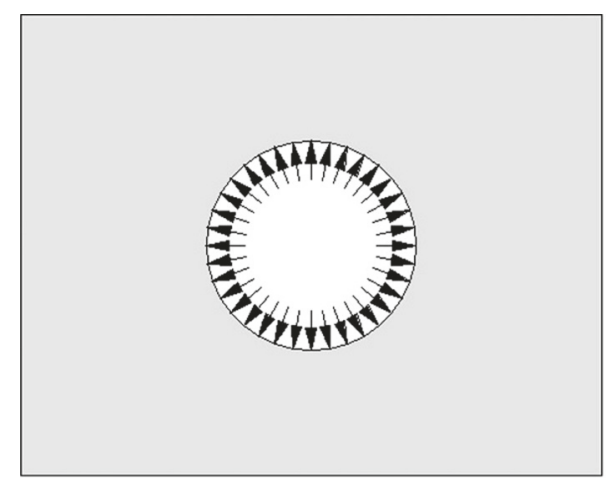

FIGURE 9: Pressure distributions caused by uniform corrosion, as applied in simulations [12].

2.3. Expansive Pressure due to Corrosion Expansion. In the presented model, expansion of the corroding reinforcement is simulated by an equivalent, imposed pressure around the reinforcing steel when full restraint by the surrounding concrete is assumed (Figures 8 and 9). The imposed pressure generated by the expansive corrosion reaction on the surrounding concrete is related to the rust volume and the rebar section loss. It also depends on the modulus of elasticity of the rust, porosity around the bar, and concrete (micro) cracking because a part of the corrosion product will go into pores and cracks and release the pressure. The correlation is, therefore, very complex and is not linear. The proposed procedure for determination of the corrosion induced pressure on the surrounding concrete by knowing the rebar section loss is described in [13]. In that paper, corrosion induced cracking of the concrete cover was studied using the lattice model.

Several important aspects of the modelling procedure need to be addressed here. In the model, the total expansion pressure depends on the geometry (i.e., the bar diameter), the loss of steel cross section, and the mechanical properties of the rust layer (the modulus of elasticity and the ratio between the density of rust versus the density of steel). When it comes to the mechanical properties of the rust layer, however, a huge range of values has been reported in the literature: for example, in [25], a value of around $0.13 \mathrm{GPa}$ for modulus of elasticity of the rust layer was reported; on the other hand, values of around $50 \mathrm{GPa}$ were found using nanoindentation technique $[15,26]$. Since this is not a topic of the current study, herein all results are expressed in terms of the expansion pressure and not in terms of loss of steel cross section. Note, however, that the pressure is related to the loss of steel cross section, as described in [13].

\section{Model Validation}

Experiments presented in [15] are used to validate the modelling approach. In the experiment, cracks opened widely and the mortar specimen failed completely during the test 


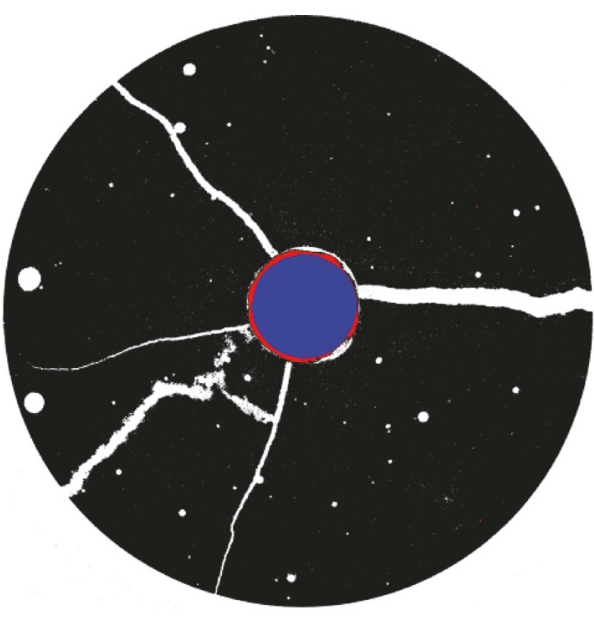

(a)

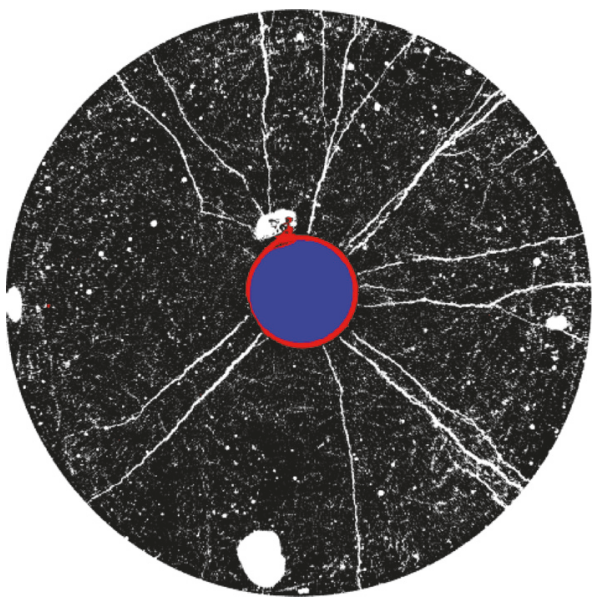

(b)

FIGURE 10: CT scan of corrosion induced cracking [13] in (a) plain mortar (b) SHCC. Blue colour denotes the steel rebar, red the rust layer, black the material matrix, and white voids and cracks.

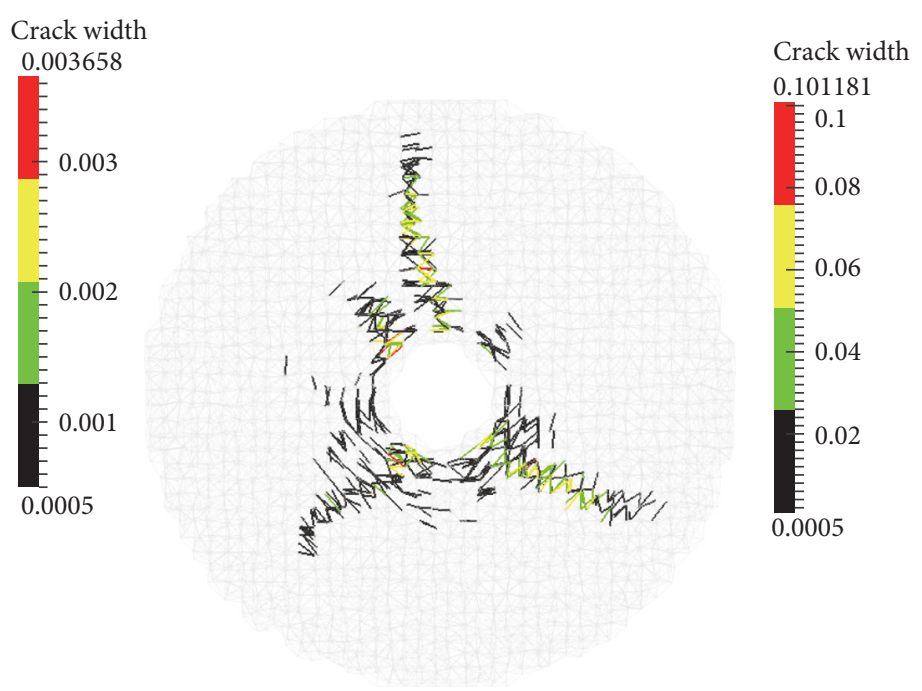

(a)

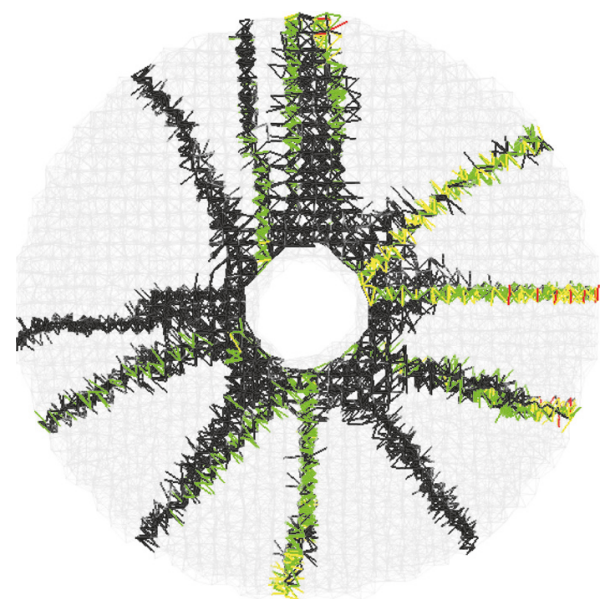

(b)

FIGURE 11: Lattice simulation of corrosion induced cracking of experiments reported in [13] (a) in mortar (imposed internal pressure of 17.32 MPa) and in (b) SHCC (imposed internal pressure of $103.58 \mathrm{MPa}$ ).

(Figure 10(a)). In contrast, the SHCC specimen showed high resistance to corrosion induced cracking. A large number of relatively narrow cracks were created (Figure 10(b)).

Numerical simulations show similar results (Figure 11). In the plain mortar once the cracks opened, the specimen could not take any more pressure and failed (Figure 11(a)). Brittle failure at small crack widths occurred. In SHCC, however, consecutive cracks were forming, allowing the specimen to withstand higher pressure resulting in ductile performance of the material (Figure 11(b)). Numerous cracks with small crack widths formed. Once the crack is formed (for any type of material), it allows some amount of corrosion product to go into existing cracks and reduces further cracking [27]. Potential benefits of using SHCC in a repair system with ongoing corrosion are further investigated and compared to experiments.

\section{Parametric Study and Discussion}

4.1. Influence of Surface Roughness and Interface Strength. In the following simulations, dimensions of the system are $80 \times 80 \mathrm{~mm}^{2}$ with a repair material thickness of $40 \mathrm{~mm}$ and a rebar of $10 \mathrm{~mm}$ diameter in its centre. The thickness of the simulated specimen (i.e., out-of-plane dimension) is $5 \mathrm{~mm}$. Sizes of the simulated specimens are not the same as those of experimentally tested specimens. However, the intention here was to qualitatively verify crack propagation 


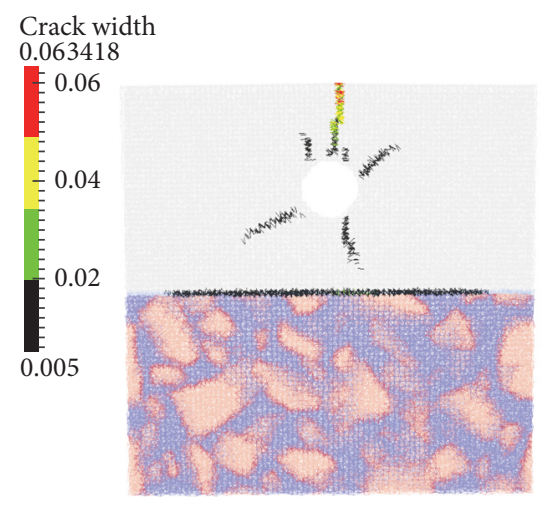

(a) Smooth surface. Interface strength of $1 \mathrm{MPa}$. Imposed pressure of $10 \mathrm{MPa}$

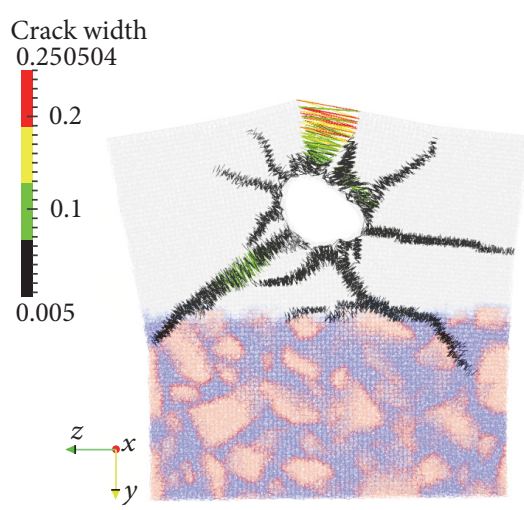

(b) Rough surface. Interface strength of $1 \mathrm{MPa}$. Imposed pressure of $26 \mathrm{MPa}$

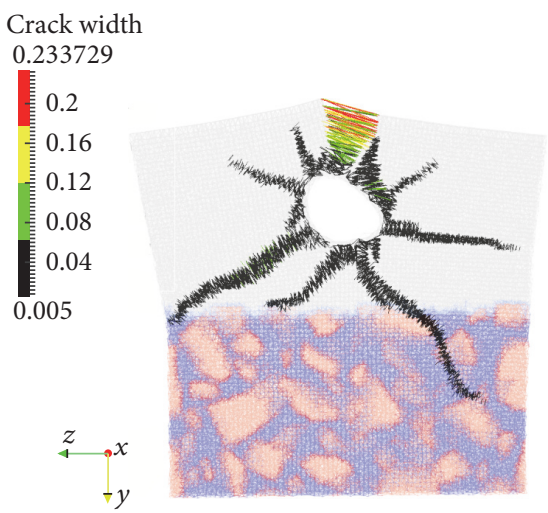

(c) Rough surface. Interface strength of $3 \mathrm{MPa}$. Imposed pressure of $26 \mathrm{MPa}$

FIGURE 12: Numerically obtained crack pattern and maximum crack widths [mm] due to the pressure imposed by expanding the bar in repair systems. Mortar is used as a repair material, influence of the substrate surface roughness, and the interface strength; top: repair material; bottom: substrate (deformation scaled 20x; note that for different samples maximum crack widths are different).

with the experiments. Therefore, the dimension ratios and the geometry in the experiments and the simulations are the same.

First, repair systems with the plain repair mortar and with the smooth and the rough substrate surface $(3 \mathrm{~mm}$ exposed aggregates) are simulated (Figure 12). In these simulations, the concrete substrate has the same tensile strength as the repair material. Three different specimens are examined: smooth surface, interface strength $1 \mathrm{MPa}$; rough surface, interface strength $1 \mathrm{MPa}$; and rough surface, interface strength $3 \mathrm{MPa}$.

In the simulation with the smooth surface, a failure of the repair system (defined as the limit when the system cannot take anymore increase in pressure) follows immediately after the onset of debonding (Figure 12(a)). The system fails at low imposed pressure with hardly any warning signs (only one vertical crack). In the test with the rough surface, however, more heterogeneity is present at the interface, enabling more stable crack development. Cracks are trapped in the roughness profiles, and this allows for further cracking to develop. As a result, the pressure that the sample can withstand is significantly higher compared to the simulation with the smooth surface (Figure 13). If appropriate roughness is provided, it seems that the interface strength does not have a significant influence in the early stage of damage (up to $20 \mathrm{MPa}$ ). However, as the pressure increases, the interface strength does play a role. With $1 \mathrm{MPa}$ interface strength, results indicate that there is a balance between debonding and substrate cracking (Figure 12(b)), while with $3 \mathrm{MPa}$ interface strength, damage occurs only through substrate cracking and no debonding is observed (Figure 12(c)).

Maximum crack widths in the SHCC repair system, under the same imposed pressure, are significantly lower compared to cracks when mortar is used as a repair material (compare Figure 16 with Figure 13). Roughness plays the same role with SHCC as a repair material. With smooth surface substrate, brittle failure at the interface occurs (Figure 14(a)). However, in the rough surface, roughness profiles

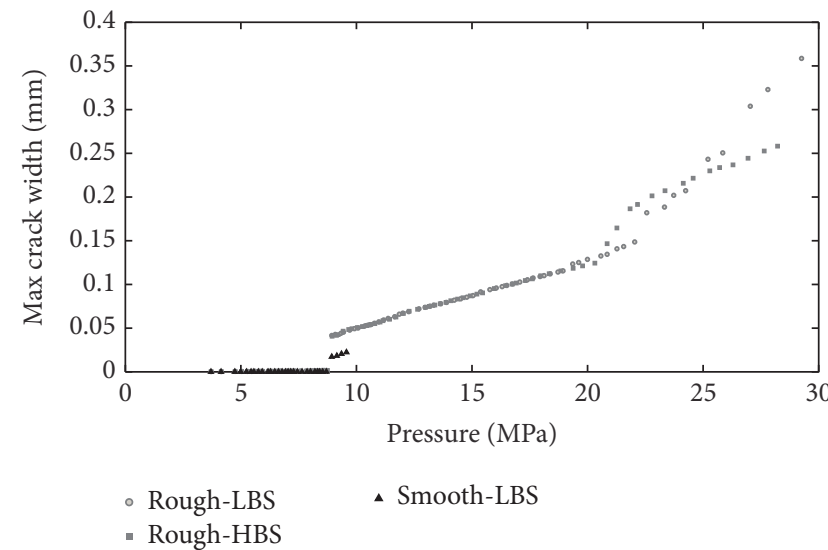

FIGURE 13: Influence of interface strength and substrate surface roughness on imposed internal pressure and corresponding maximum crack widths prior to repair system failure. Plain mortar is used as a repair material (LBS corresponds to interface strength $1 \mathrm{MPa}$ and HBS to interface strength $3 \mathrm{MPa}$ ).

are interlocking the crack and the failure is more ductile (Figure 14(b)).

The same is observed experimentally (Figure 15). Smooth specimen exhibits large debonding, resulting in interface failure (Figure 15(a)). With grooved surface, two specimens are tested. One specimen behaves similarly to the simulated specimen with the lower interface strength (compare Figure 15(b) and 14(b)). Sample 2 (sealed cured for 7 days) behaves similarly to the specimen simulated with the higher interface strength (compare Figure 15(c) and 14(c)). Note, however, that differences in these two crack patterns are minor and that, in both cases, grooves interlocked the crack from the repair material and directed it through the substrate. This indicates that, with the rough surface, interface strength becomes less important than with the smooth surface. Similar benefits of higher substrate roughness (without the need of 


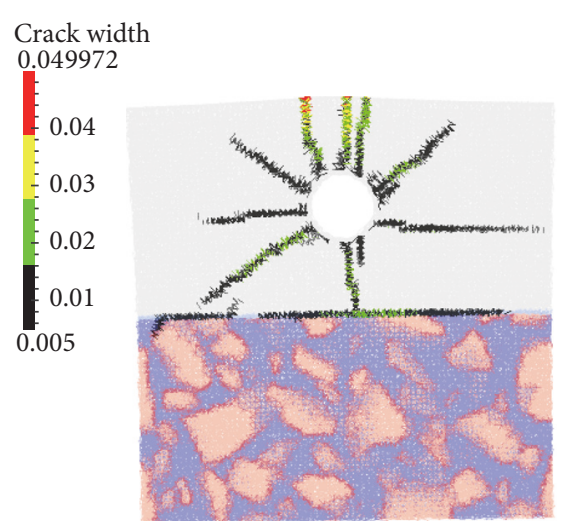

(a) Smooth surface. Interface strength of $1 \mathrm{MPa}$. Pressure at failure $(24 \mathrm{MPa})$

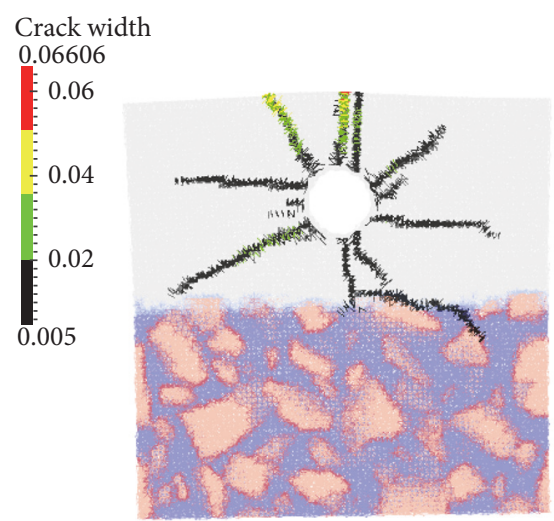

(b) Rough surface. Interface strength of $1 \mathrm{MPa}$. Imposed pressure of $26 \mathrm{MPa}$

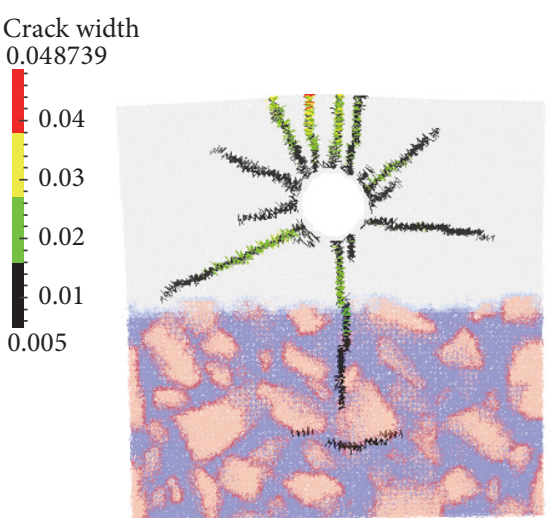

(c) Rough surface. Interface strength of $3 \mathrm{MPa}$ Imposed pressure of $26 \mathrm{MPa}$

FIGURE 14: Numerically obtained crack pattern and maximum crack widths due to the pressure imposed by expanding bar in repair systems. SHCC is used as a repair material, influence of the substrate surface roughness, and the interface strength (deformation scaled 20x; note that for different samples maximum crack widths are different).

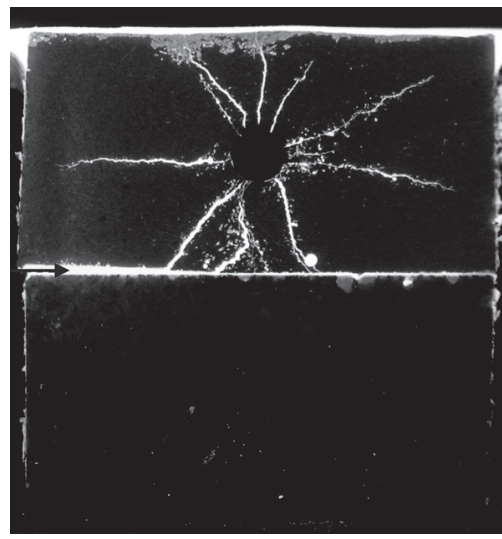

(a) SHCC: smooth surface. Complete delamination (interface failure)

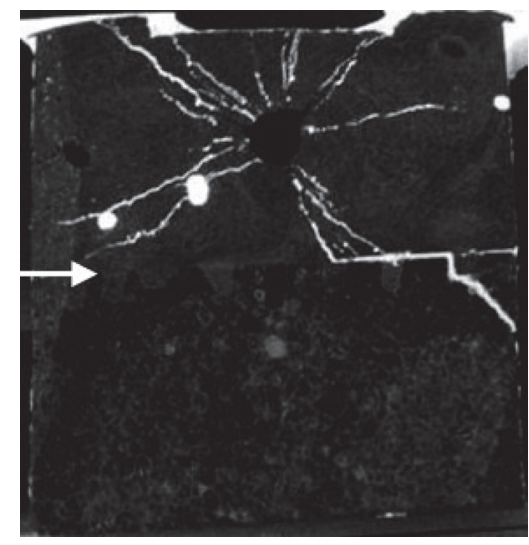

(b) SHCC: grooved surface. Sample 1 (groove interlocking the crack to the substrate)

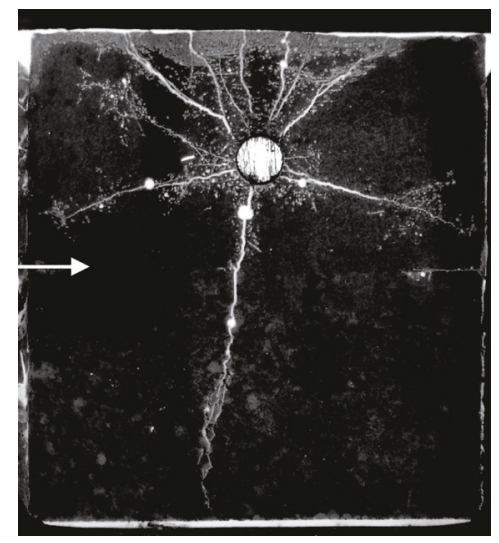

(c) SHCC: grooved surface. Sample 2 (groove interlocking the crack to the substrate)

FIGURE 15: Experimentally obtained damage patterns when SHCC is used as a repair material (top: repair material; bottom: mortar substrate; interface is indicated with the arrow); samples are epoxy impregnated and imaged under UV light.

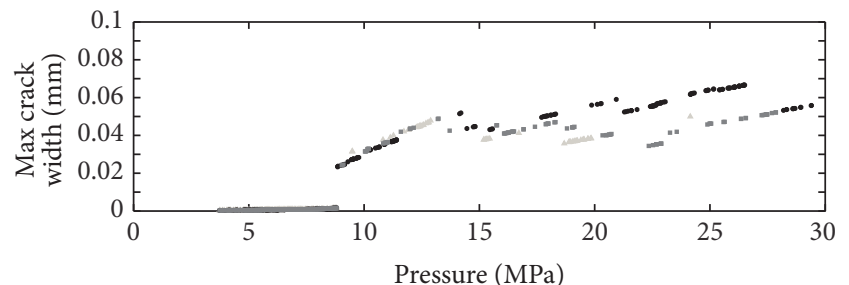

Smooth surface-LBS

- Rough surface-LBS

- Rough surface-HBS

FIGURE 16: Influence of interface strength and substrate surface roughness on imposed internal pressure and corresponding maximum crack widths prior to repair system failure. SHCC is used as a repair material (LBS corresponds to interface strength $1 \mathrm{MPa}$ and HBS to interface strength of $3 \mathrm{MPa}$ ). increasing interface strength) were also observed in performance of the repair system in flexure tests [20] and under drying shrinkage [28].

4.2. Influence of Repair Material. Numerically obtained crack patterns with different repair materials are given in Figure 17. Crack distribution is compared to experimentally obtained cracks. At the same pressure levels (around $26 \mathrm{MPa}$ ), maximum crack width inside the SHCC is a few times smaller compared to the repair mortar (Figure 17). More cracks form, with small cracks widths (up to $70 \mu \mathrm{m}$ ). However, the substrate is still brittle and SHCC does not prevent cracks from propagating into the substrate.

Similar results are obtained experimentally (see Figure 18). While SHCC exhibits multiple microcracking, in the 


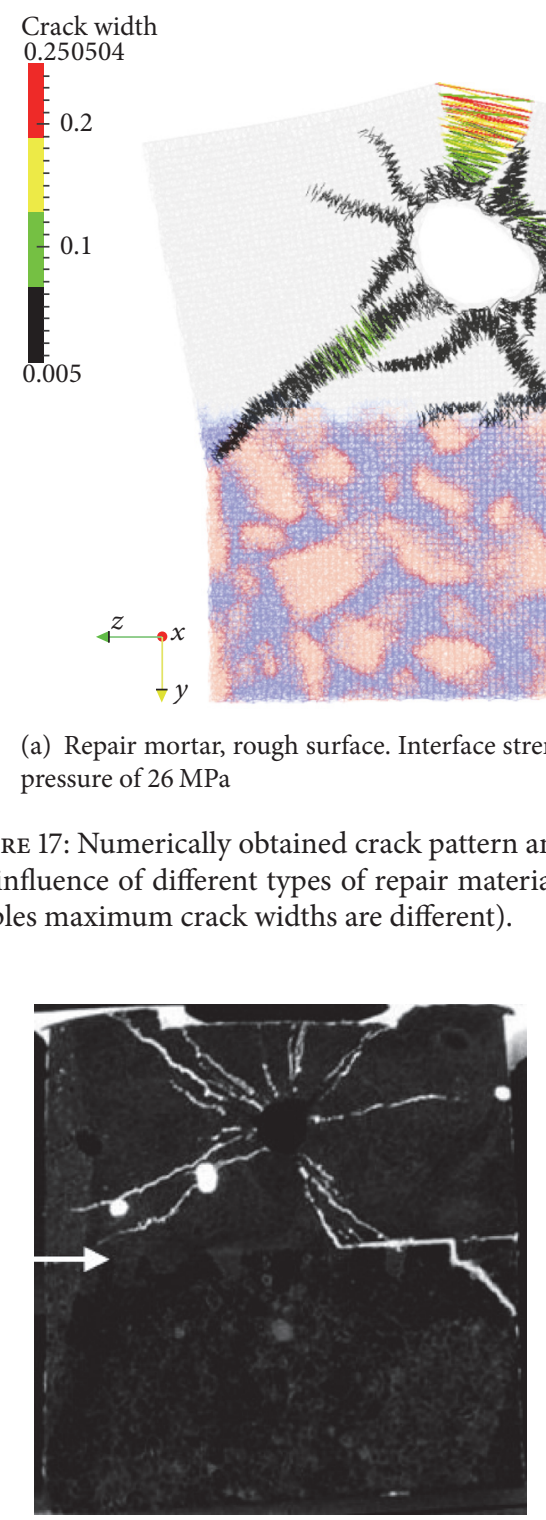

(a) Repair mortar samples maximum crack widths are different).

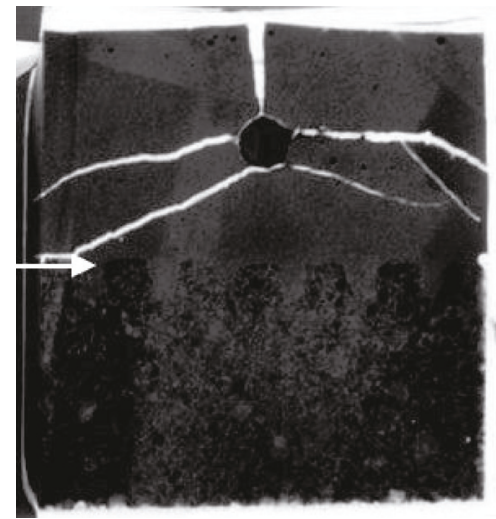

(b) SHCC

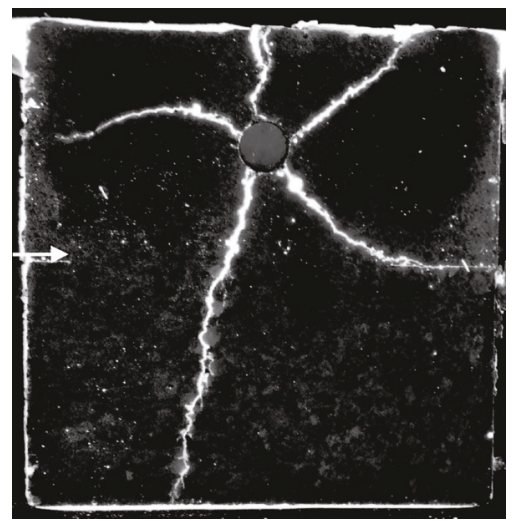

(c) Commercial repair material

FIGURE 18: Experimentally obtained damage patterns (top: repair material; bottom: mortar substrate; interface is indicated with the arrow); samples are epoxy impregnated and imaged under UV light.

repair mortar a wide crack opens above the reinforcing bar. The commercial repair material shows a similar behaviour (Figure 18(c)). This material contains also fibres but it does not have strain hardening capacity nor the controlled crack widths.

With the interface strength of $1 \mathrm{MPa}$ (around $30 \%$ of the matrix strength), a simulated damage corresponds well to experimentally obtained damage in repair systems. This is valid both when the repair mortar and the SHCC are used as repair materials. In experiments, however, there is less cracking in the mortar substrate (compare Figure 17(a) with Figure 18(a)). This could be a result of the substrate strength used in the simulations. In the simulations, the mortar substrate is assumed to have the same tensile strength

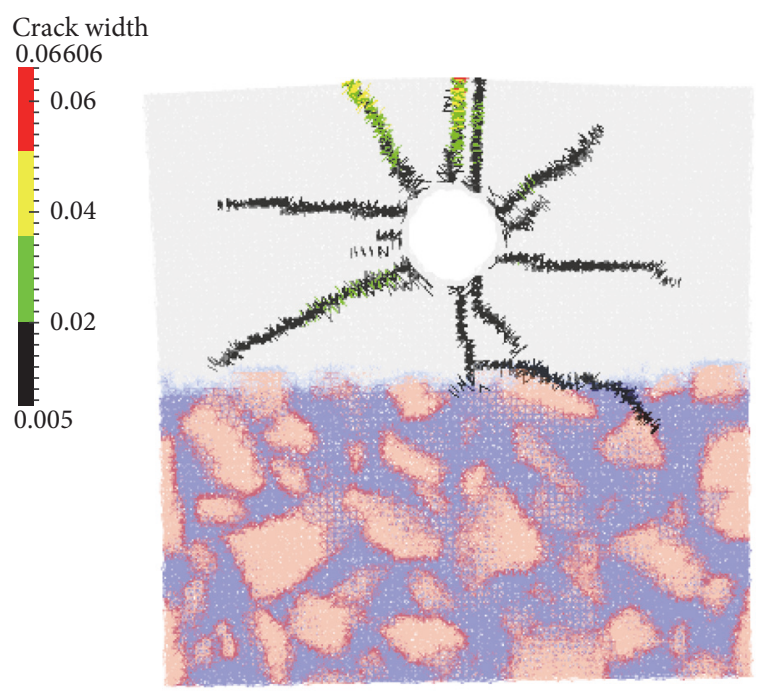

(b) SHCC, rough surface. Interface strength of $1 \mathrm{MPa}$. Imposed pressure of $26 \mathrm{MPa}$

maximum crack widths due to the pressure imposed by expanding bar in repair systems and influence of different types of repair materials; top: repair material; bottom: substrate (deformation scaled 20x; note that for different 


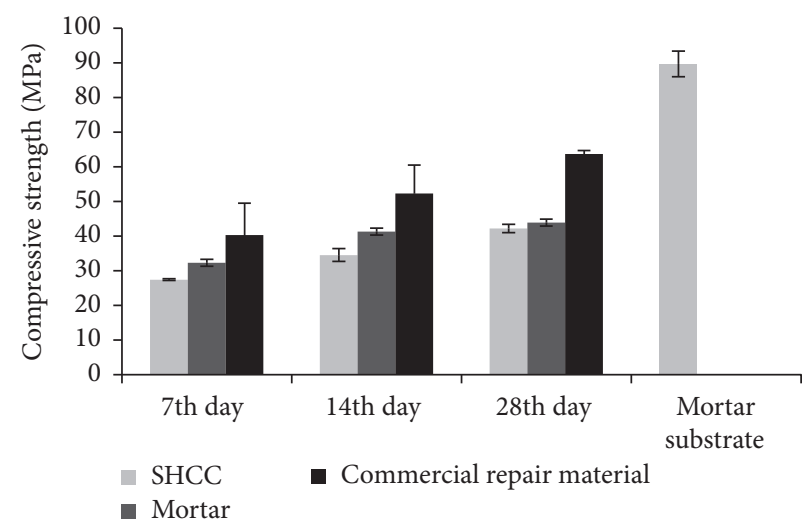

FIGURE 19: Compressive strength results of the repair materials and mortar substrate used in this study.

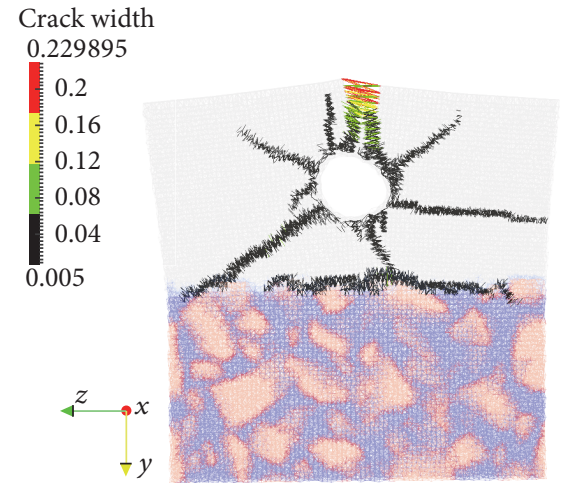

(a) Repair mortar, rough surface. Interface strength of $1 \mathrm{MPa}$. Imposed pressure of $26 \mathrm{MPa}$

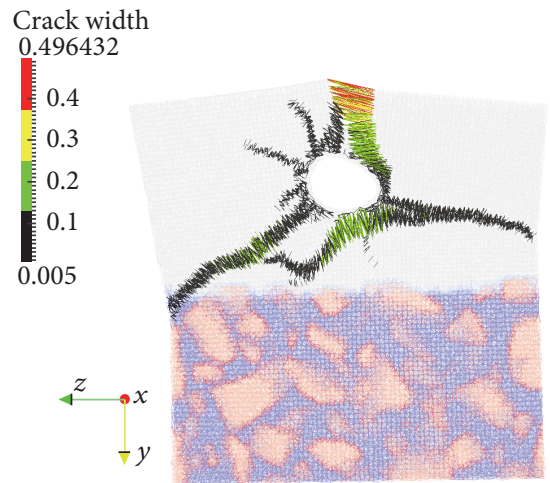

(b) Repair material, rough surface. Interface strength of $3 \mathrm{MPa}$. Imposed pressure of $26 \mathrm{MPa}$

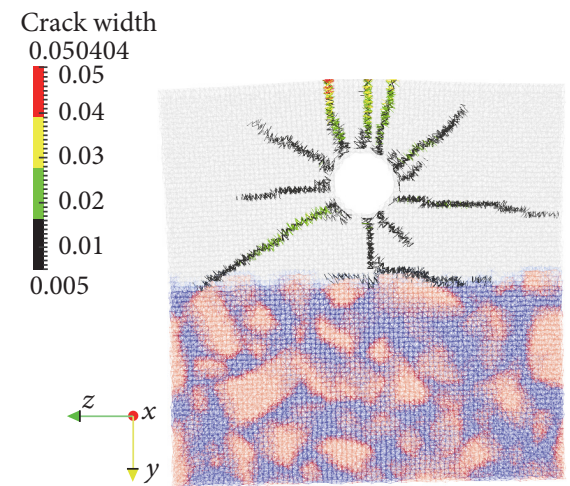

(c) SHCC, rough surface. Interface strength of $1 \mathrm{MPa}$. Imposed pressure of $26 \mathrm{MPa}$

FIGURE 20: Numerically obtained crack pattern and maximum crack widths due to the pressure imposed by expanding bar in repair systems. Substrate is stronger than repair material, influence of the interface strength, and type of the repair material; top: repair material; bottom: substrate (deformation scaled 20x; note that for different samples maximum crack widths are different).

crack. Therefore, cracking of the repair material and debonding are the only ways for releasing stresses (Figure 20(a)). With the high interface strength, there is no debonding and the pressure build-up results only in cracking of the repair material. At the same imposed pressure, this repair system reaches larger crack widths compared to a partially debonded specimen (compare Figure 20(a) and 20(b)). This indicates that, with the strong substrate, some debonding is beneficial because stresses will be partially relieved.

In Figures 20(c) and 21, the damage and the maximum cracks widths are shown when SHCC is used as a repair material. For the same pressure, maximum crack widths are significantly smaller for the SHCC repair system. Furthermore, neither the interface strength nor the substrate strength seems to have a significant influence on crack widths. However, there is an influence on the crack pattern, as low interface strength leads to more debonding (Figure 22).

\section{General Discussion}

If the reinforcing bar surrounded by a newly placed repair material continues to corrode (due to either higher permeability of the repair material, restrained shrinkage cracking, or inadequate cleaning of the bar), further damage in the repair system can be controlled with a SHCC type of repair material. Crack widths and the failure mode in the repair system with the repair (plain) mortar are very sensitive to the type of the surface preparation and substrate strength. With SHCC, the failure mode and crack widths are still sensitive to the substrate surface preparation, but there is less sensitivity to the substrate strength. Furthermore, under these loading conditions, independent of the type of repair material, the local interface strength becomes less important if the substrate surface is rough. This is because a rough surface enables more cracking and higher ductility during failure. Roughness profiles are interlocking cracks in the substrate (similar to $[18,28]$ ) thereby preventing complete delamination. On the other hand, some debonding (as long as it does not result in complete delamination) may be beneficial for stress relief and smaller cracks in the repair material and the substrate.

Interface strength in this paper is studied by combining modelling and experimental testing. Once the tests are performed, the interface strength in the simulation is 


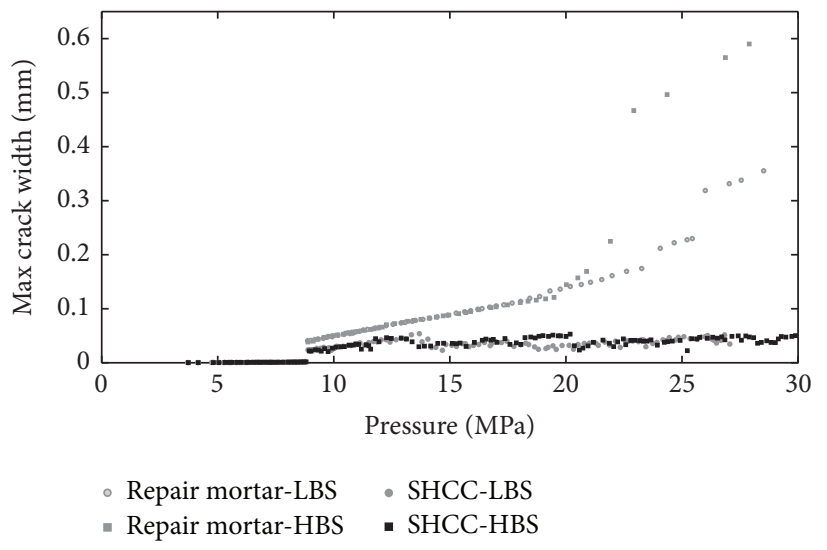

Figure 21: Pressure build-up and corresponding maximum crack widths in the system with the substrate stronger than the repair material (LBS corresponds to the interface strength of $1 \mathrm{MPa}$ and $\mathrm{HBS}$ to the interface strength of $3 \mathrm{MPa}$ ).

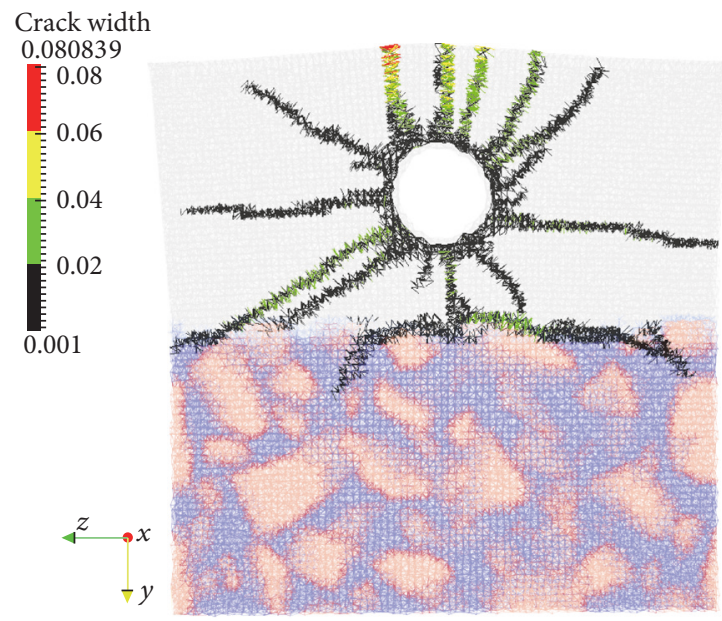

(a) SHCC, rough surface. Interface strength of $1 \mathrm{MPa}$. Imposed pressure of $39 \mathrm{MPa}$

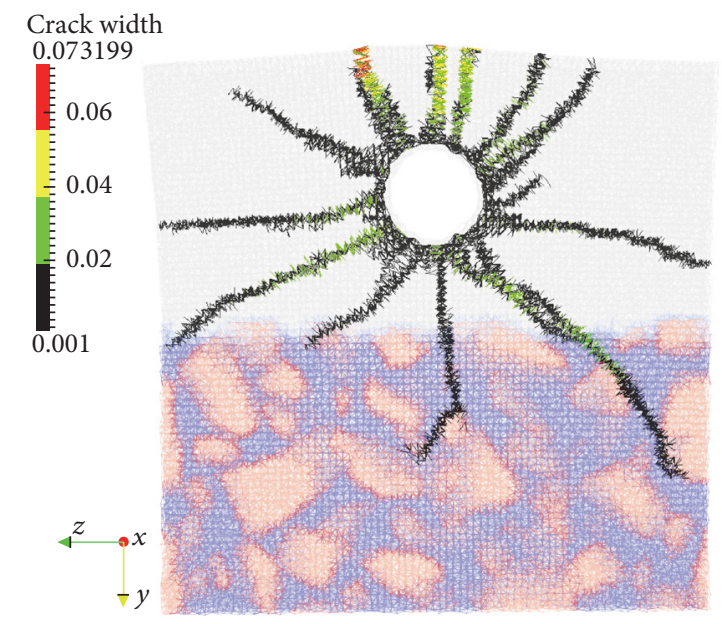

(b) SHCC, rough surface. Interface strength of $3 \mathrm{MPa}$. Imposed pressure of $39 \mathrm{MPa}$

FIGURE 22: Numerically obtained crack pattern and maximum crack widths due to the pressure imposed by expanding bar in repair systems. Substrate is stronger than repair material and influence of interface strength; top: repair material; bottom: substrate (note that for different samples maximum crack widths are different).

adjusted so that the simulated fracture corresponds to the experimentally obtained crack pattern [29]. This should be then performed for various boundary conditions. Only in this way the interface strength, which is a micromechanical property, can be investigated at mesoscale. In these simulations and with these boundary conditions, the same fracture behaviour as in experiments was obtained when the interface strength is around $30 \%$ of the strength of the repair material. Similar results were obtained for flexure tests performed in [20].

\section{Conclusions}

In this paper, the influence of ongoing corrosion on damage development in repair systems is studied. For this purpose, the lattice fracture model is used. Simulated results were verified by accelerated corrosion experiments. Based on the presented results and discussions, the following conclusions can be drawn:

(i) Similar to the performance of the SHCC repair system in drying shrinkage, a smooth surface of the substrate is not advised, as it leads to brittle failure of the repair system. With SHCC as a repair material, the benefits of distributed cracking cannot be fully utilised.

(ii) With a rough surface, the interface strength becomes less important. Grooves enable interlocking and direct the crack to the substrate.

(iii) With a rough surface, SHCC repair enables distributed cracking with small crack widths (up to several times smaller compared to repair mortar). More warning signs are present prior to final failure of the repair system. 
(iv) Due to ongoing corrosion (further corrosion of reinforcing bar inside the repair material), crack propagation and failure modes are predicted and explained with the lattice model. Interface strength in this way is implicitly studied. With the interface tensile strength equal to $30 \%$ of the matrix tensile strength, numerically predicted behaviour corresponds to experimentally observed behaviour.

(v) The balance between cracking and debonding is very sensitive to local material properties of the repair material, substrate, and interface. Local debonding adjacent to the crack, as long as it does not result in complete delamination, can be beneficial, as it enables reduction of stresses and smaller crack widths in the repair system.

\section{Conflicts of Interest}

The authors declare that they have no conflicts of interest.

\section{Acknowledgments}

Financial support by the Dutch Technology Foundation (STW) for the project 10981, "Durable Repair and Radical Protection of Concrete Structures in View of Sustainable Construction," is gratefully acknowledged.

\section{References}

[1] L. Bertolini, B. Elsener, P. Pedeferri, E. Redaelli, and R. B. Polder, Corrosion of Steel in Concrete: Prevention, Diagnosis, Repair, John Wiley \& Sons, New York, NY, USA, 2013.

[2] M. Raupach, "Chloride-induced macrocell corrosion of steel in concrete-theoretical background and practical consequences," Construction and Building Materials, vol. 10, no. 5, pp. 329-338, 1996.

[3] J. A. Gonzalez, S. Algaba, and C. Andrade, "Corrosion: of reinforcing bars in carbonated concrete," British Corrosion Journal, vol. 15, no. 3, pp. 135-139, 1980.

[4] C. Alonso, C. Andrade, J. Rodriguez, and J. M. Diez, "Factors controlling cracking of concrete affected by reinforcement corrosion," Materials and Structures, vol. 31, no. 211, pp. 435-441, 1998.

[5] Y. Liu and R. E. Weyers, "Modeling the time-to-corrosion cracking in chloride contaminated reinforced concrete structures," ACI Materials Journal, vol. 95, no. 6, pp. 675-681, 1998.

[6] P. R. Vassie, "The influence of steel condition on the effectiveness of repairs to reinforced concrete," Construction and Building Materials, vol. 3, no. 4, pp. 201-207, 1989.

[7] A. M. Vaysburd and P. H. Emmons, "How to make today's repairs durable for tomorrow-corrosion protection in concrete repair," Construction and Building Materials, vol. 14, no. 4, pp. 189-197, 2000.

[8] C. Christodoulou, C. Goodier, S. Austin, J. Webb, and G. K. Glass, "Diagnosing the cause of incipient anodes in repaired reinforced concrete structures," Corrosion Science, vol. 69, pp. 123-129, 2013.

[9] T. Kamada and V. C. Li, "Effects of surface preparation on the fracture behavior of ECC/concrete repair system," Cement and Concrete Composites, vol. 22, no. 6, pp. 423-431, 2000.
[10] M. D. Lepech and V. Li, "Long term durability performance of engineered cementitious composites," Restoration of Buildings and Monuments, vol. 12, no. 2, pp. 119-132, 2006.

[11] K. Kobayashi, T. Iizuka, H. Kurachi, and K. Rokugo, "Corrosion protection performance of high performance fiber reinforced cement composites as a repair material," Cement and Concrete Composites, vol. 32, no. 6, pp. 411-420, 2010.

[12] S. J. Pantazopoulou and K. D. Papoulia, "Modeling covercracking due to reinforcement corrosion in RC structures," Journal of Engineering Mechanics, vol. 127, no. 4, pp. 342-351, 2001.

[13] B. Šavija, M. Luković, J. Pacheco, and E. Schlangen, "Cracking of the concrete cover due to reinforcement corrosion: a twodimensional lattice model study," Construction and Building Materials, vol. 44, pp. 626-638, 2013.

[14] K. Kobayashi, S. C. Paul, and G. P. van Zijl, "Reinforcing bar corrosion," in A Framework for Durability Design with Strain-Hardening Cement-Based Composites (SHCC), pp. 14770, Springer, Berlin, Germany, 2017.

[15] B. Šavija, M. Luković, S. A. S. Hosseini, J. Pacheco, and E. Schlangen, "Corrosion induced cover cracking studied by X-ray computed tomography, nanoindentation, and energy dispersive X-ray spectrometry (EDS)," Materials and Structures, vol. 48, no. 7, pp. 2043-2062, 2015.

[16] E. Schlangen and Z. Qian, "3D modeling of fracture in cementbased materials," Journal of Multiscale Modeling, vol. 1, no. 2, pp. 245-261, 2009.

[17] E. Schlangen and J. G. M. van Mier, "Experimental and numerical analysis of micromechanisms of fracture of cementbased composites," Cement and Concrete Composites, vol. 14, no. 2, pp. 105-118, 1992.

[18] L. Liu, G. Ye, E. Schlangen et al., "Modeling of the internal damage of saturated cement paste due to ice crystallization pressure during freezing," Cement and Concrete Composites, vol. 33, no. 5, pp. 562-571, 2011.

[19] B. Šavija, D. Liu, G. Smith, K. R. Hallam, E. Schlangen, and P. E. J. Flewitt, "Experimentally informed multi-scale modelling of mechanical properties of quasi-brittle nuclear graphite," Engineering Fracture Mechanics, vol. 153, pp. 360-377, 2016.

[20] M. Luković, H. Dong, B. Šavija, E. Schlangen, G. Ye, and K. van Breugel, "Tailoring strain-hardening cementitious composite repair systems through numerical experimentation," Cement and Concrete Composites, vol. 53, pp. 200-213, 2014.

[21] E. N. Landis and J. E. Bolander, "Explicit representation of physical processes in concrete fracture," Journal of Physics D: Applied Physics, vol. 42, no. 21, Article ID 214002, 2009.

[22] E. Schlangen, "Crack development in concrete, Part 1: fracture experiments and CT-scan observations," Key Engineering Materials, vol. 385-387, pp. 69-72, 2008.

[23] E. J. Garboczi, “Three-dimensional mathematical analysis of particle shape using X-ray tomography and spherical harmonics: application to aggregates used in concrete," Cement and Concrete Research, vol. 32, no. 10, pp. 1621-1638, 2002.

[24] Z. Qian, E. J. Garboczi, G. Ye, and E. Schlangen, "Anm: a geometrical model for the composite structure of mortar and concrete using real-shape particles," Materials and Structures, vol. 49, no. 1-2, pp. 149-158, 2016.

[25] S. Caré, Q. T. Nguyen, V. L’Hostis, and Y. Berthaud, “Mechanical properties of the rust layer induced by impressed current method in reinforced mortar," Cement and Concrete Research, vol. 38, no. 8-9, pp. 1079-1091, 2008. 
[26] Y. Zhao, H. Dai, and W. Jin, "A study of the elastic moduli of corrosion products using nano-indentation techniques," Corrosion Science, vol. 65, pp. 163-168, 2012.

[27] H. S. Wong, Y. X. Zhao, A. R. Karimi, N. R. Buenfeld, and W. L. Jin, "On the penetration of corrosion products from reinforcing steel into concrete due to chloride-induced corrosion," Corrosion Science, vol. 52, no. 7, pp. 2469-2480, 2010.

[28] M. Lukovic, B. avija, E. Schlangen, G. Ye, and K. van Breugel, "A 3D lattice modelling study of drying shrinkage damage in concrete repair systems," Materials, vol. 9, no. 7, p. 575, 2016.

[29] A. H. J. M. Vervuurt, Interface fracture in concrete [Ph.D. thesis], Delft University of Technology, Delft, Netherlands, 1997. 

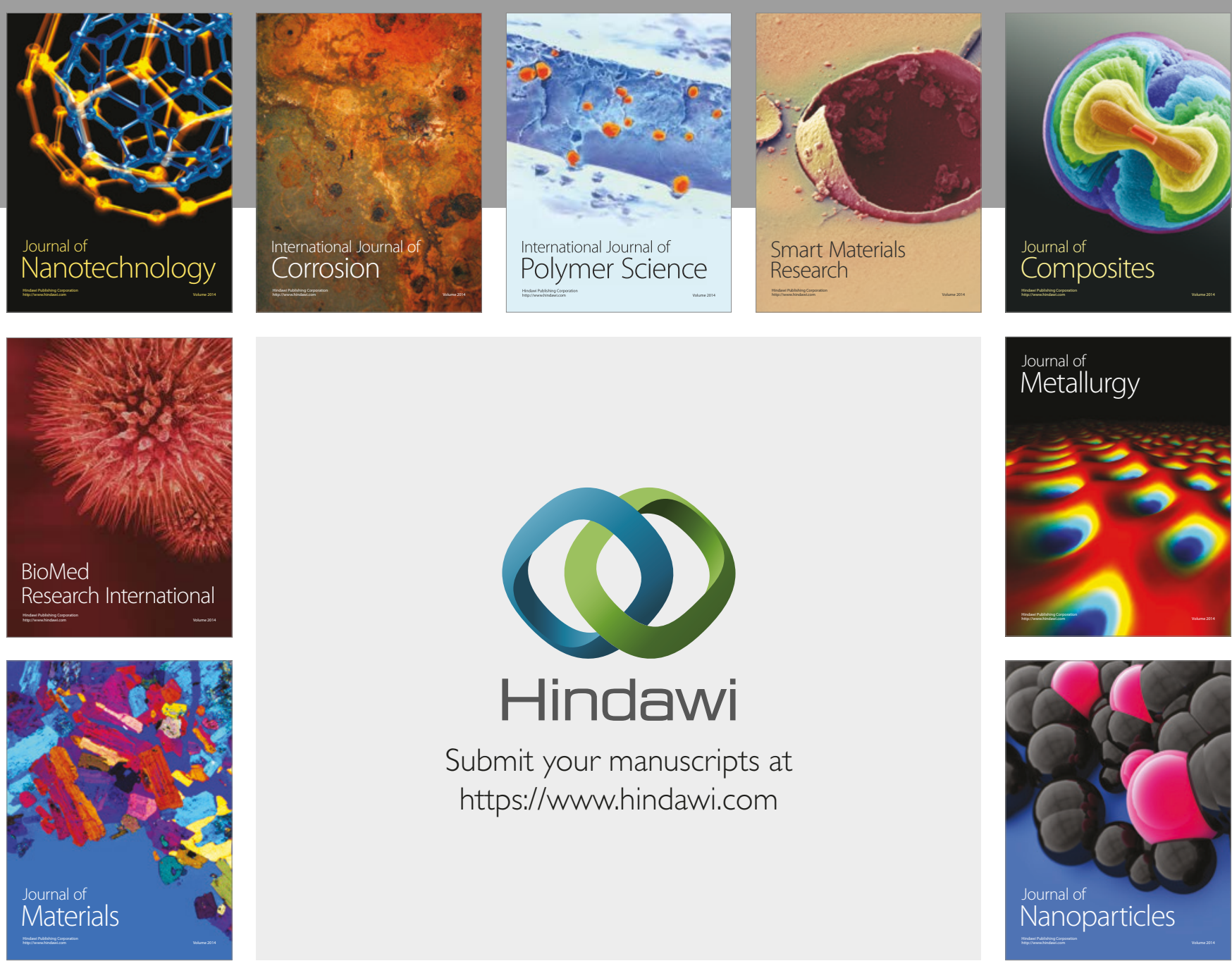

\section{Hindawi}

Submit your manuscripts at

https://www.hindawi.com
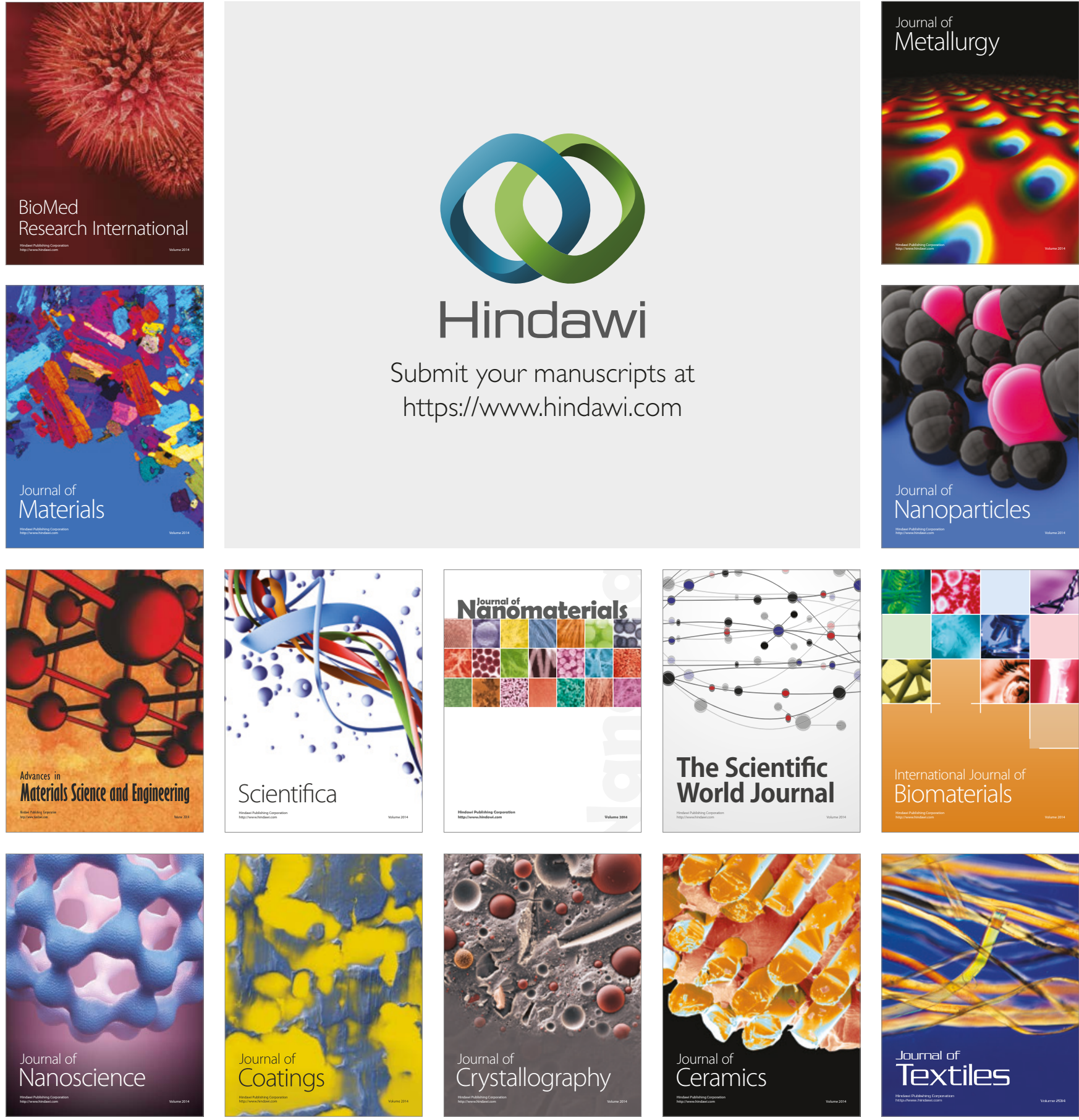

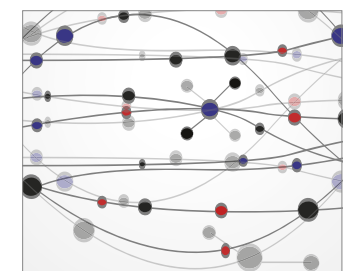

The Scientific World Journal
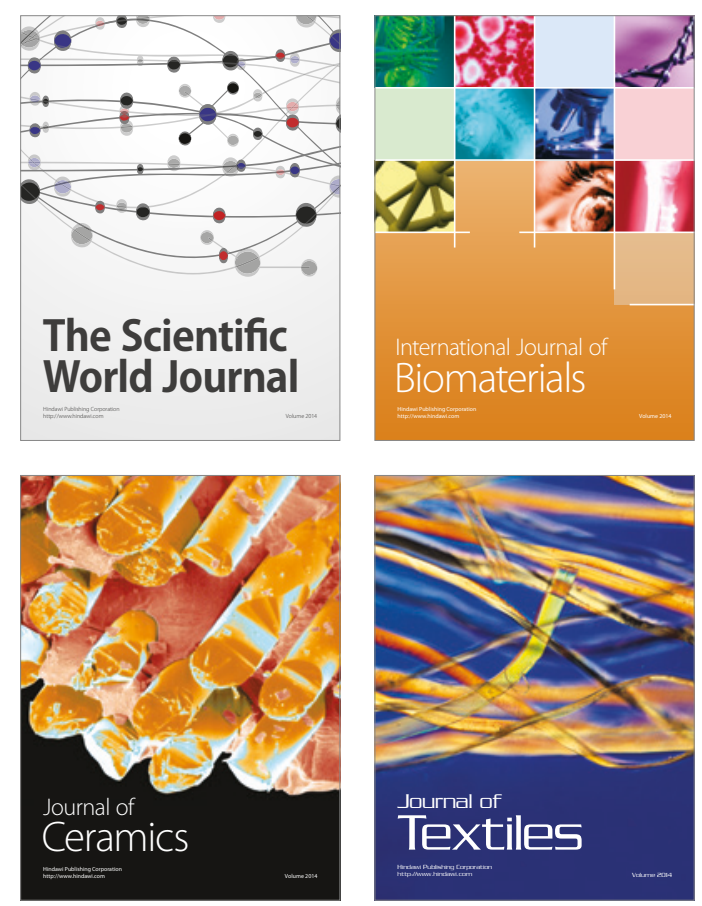